\title{
ANALYSIS OF DIFFERENTIAL PREDATION
}

\author{
B. F. J. MANLY \\ Biometrics Unit, University of Otago, P.O. Box 56, Dunedin, New Zealand \\ Received 9.xi.77
}

I would like to make two comments on the paper by Maskell et al. (1977) published recently in this journal.

In the paper the authors considered the results of 24 experiments involving sticklebacks eating pale and light coloured prey. The results of a single experiment are of the following form.

$\begin{array}{lccc} & \text { Eaten } & \text { Left } & \begin{array}{c}\text { Total } \\ \text { available }\end{array} \\ \text { Pale prey } & \mathrm{a} & \mathrm{c} & \mathrm{a}+\mathrm{c} \\ \text { Dark prey } & \mathrm{b} & \mathrm{d} & \mathrm{b}+\mathrm{d}\end{array}$

My first comment is that if such data are to be analysed using the computer program GLIM (Nelder, 1974) then a double log model would be more appropriate than the log-linear model that was used by Maskel $e t$ al. I have given some reasons for this in a paper in this journal (Manly, 1976). Essentially it is a question of how the time period of a survival experiment affects the results.

However, my second comment is that a much simpler method for analysing Maskell et al.'s data exists, based upon the use of $\beta$ coefficients (e.g., see Manly, 1972). These are estimates of the probability of a pale prey being taken first, assuming that predators are faced with equal numbers of pale and dark prey. For the results given in Maskell et al.'s tables 2A, 2B and $2 \mathrm{C}$ the $\beta$ estimates are as follows:

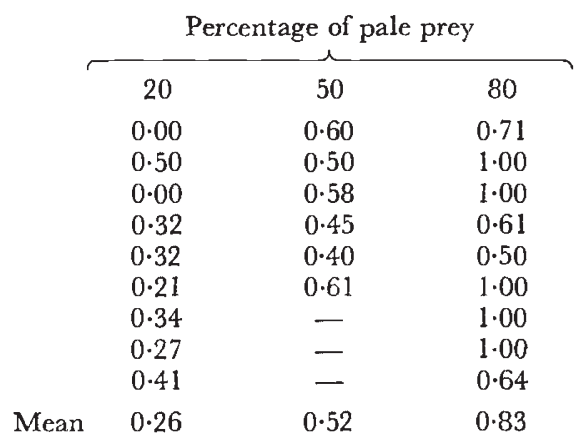

My linear model for apostatic selection seems to apply (Manly, 1973); i.e., there seems to be a linear change in the value of $\beta$ when the frequency of one type of prey changes.

\section{REFERENGES}

MANLY, B. F. J. 1972. Tables for the analysis of selective predation experiments. Res. Popul. Ecol., 14, 74-81. 
MANLY, B. F. J. 1973. A linear model for frequency-dependent selection by predators. Res. Popul. Ecol., 14, 137-150.

MANLY, B. F. J. 1976. Some examples of double exponential fitness functions. Heredity, $36,229-234$.

MASKELL, M., PARKIN, D. T., AND VERSPOOR, E. 1977. Apostatic selection by sticklebacks upon a dimorphic prey. Heredity, 39, 83-89.

NeLder, J. A. 1974. Glim Manual. Distributed by the Numerical Algorithms Group, 13 Banbury Road, Oxford. 